\title{
СУЩНОСТЬ ИНВЕСТИЦИЙ И ИХ ЗНАЧЕНИЕ ДЛЯ РАЗВИТИЯ НАЦИОНАЛЬНОЙ ЭКОНОМИКИ
}

\author{
АБУ ШАКЕР МИРВАТ \\ аспирант Белорусского национального технического университета
}

\begin{abstract}
Аннотация:
В данной статье рассматривается процесс привлечения инвестиций как важного механизма решения проблем социально-экономического развития страны, выделяются проблемы привлечения иностранных инвестиций, анализируются механизмы и способы привлечения иностранных инвестиций в национальную экономику. Также представлена поэтапная классификация целей инвестирования, форм инвестиций и мер на уровне государственного управления для их привлечения.
\end{abstract}

\section{ВВЕДЕНИЕ}

В условиях глобализации современного мира национальные экономики отдельных государств начинают приобретать все более открытый характер. Чем более открыта экономика той или иной страны, тем важнее для нее становится достигнутый ею уровень конкурентоспособности. Кто выигрывает в конкурентной борьбе - тот имеет возможность сохранять рабочие места, повышать доходы населения, модернизировать производство. По общему мнению специалистов, это невозможно сделать без адекватного инвестиционного процесса, вызывающего, с одной стороны, необходимые инновационные изменения и ведущего, с другой стороны, к позитивным структурным сдвигам в хозяйстве. Снижение инвестиционной активности в любой стране трактуется как серьезная угроза национальной безопасности. Перед переходной экономикой неизбежно стоит задача развития высокотехнологичных обрабатывающих производств с значительной добавленной стоимостью. Именно динамично растущие инвестиции с материализованными в них инновациями, трансформируясь в создание новых конкурентоспособных производств, являются не только движущей силой развития производства, но способны обеспечивать высокие темпы и качество экономического роста.

\section{РЕЗУЛЬТАТЫ И ИХ ОБСУЖДЕНИЕ}

В современном мире практически не осталось стран, которые не вовлечены в процессы международного инвестиционного сотрудничества. В настоящее время стало ясно, что устойчивое экономическое развитие страны невозможно без ее участия в мирохозяйственных процессах, в том числе без активного привлечения инвестиций из-за рубежа.

При помощи иностранных инвестиций решаются такие задачи, как освоение и удержание своих «ниш» на диверсифицированных международных рын- 
ках, приобщение к научно-техническому управленческому опыту других стран, преодоление таможенных барьеров отдельных стран и региональных группировок, структурная перестройка международного разделения труда.

Иностранные инвестиции, таким образом, обеспечивают не только деньги, но также опыт в области управления, «ноу-хау», и, нередко, доступ к рынкам. Передача опыта и технологий возможна также без крупных капиталовложений, путем франшизных, лизинговых или лицензионных соглашений. Конкуренция, привносимая иностранными инвесторами, заставляет местных производителей и компании, предоставляющие услуги, приспосабливаться, повышая эффективность своего производства.

Качественный и значительный экономический эффект дает создание предприятий с иностранными инвестициями или совместных предприятий, открывающих доступ стране-реципиенту к современной технике и технологии, программам и системам организации труда и заработной платы, достижениям маркетинга и менеджмента, приобщающих к мировому опыту внешнеэкономической деятельности.

Создание совместных предприятий является условием, ограничивающим валютную задолженность, так как в этом случае страна берет у других стран меньше кредитов и займов и тем самым при создании предприятий с иностранными инвестициями не увеличивает свою кредиторскую задолженность.

Инвестирование - это явление с глубокими историческими корнями. Инвестиции возникли в условиях становления товарно-денежных отношений под влиянием конкретных потребностей как способ разрешения противоречий между потребностями и возможностями расширения производства товаров и услуг.

Сам по себе термин «инвестиции» происходит от латинского слова «invest» и означает «вкладывать». В наиболее широком смысле слово «инвестировать» означает: «расстаться с деньгами сегодня, чтобы получить большую их сумму в будущем» [1]. При этом прирост капитала должен быть достаточным, чтобы компенсировать инвестору отказ от использования собственных средств на потребление в текущем периоде, вознаградить его за риск и возместить потери от инфляции в будущем периоде[2, 3 с.].

Существует множество определений термина «инвестиции однако, наиболее полным представляется развернутое определение, данное Н.Я. Петраковым: «Инвестиции - это денежные средства, целевые банковские вклады, паи, акции и ценные бумаги, технологии, машины и оборудование, лицензии, в том числе и на товарные знаки, кредиты, любое другое имущество или имущественные права, интеллектуальные ценности, вкладываемые в объекты предпринимательской деятельности и других видов деятельности с целью получения прибыли (дохода) и достижения положительного социального эффекта» [3, 705 с.].

Некоторые различия в трактовках инвестиций не меняют сущности понимания инвестиций большинством экономистов. В основном, инвестиции трактуются как некая форма вложения капитала либо как затраты денежных средств на воспроизводство капитала. Такое понимание инвестиций, на взгляд автора, страдает ограниченностью и не раскрывает глубинного экономического смысла 
инвестиций, их отличий от категории капитала. По мнению автора, капитал и инвестиции соотносятся диалектически как форма и содержание. Капитал есть единство всех основных элементов целого, его свойств и связей. Инвестиции есть способ существования содержания, то есть капитала, неотделимые и служащие его выражением, т.е. капитал и инвестиции выступают как единство формы и содержания.

Инвестиции - это процесс смены форм капитала, преобразования первоначальных ресурсов и ценностей в инвестиционные затраты и превращение вложенных средств в прирост капитальной стоимости в форме дохода или социального эффекта.

Необходимо выделить следующие сущностные характеристики категории инвестиций:

- предмет инвестиций - временно свободный экономический ресурс в денежной, материальной и интеллектуальной формах;

- субъекты инвестиций - собственник предмета инвестиций и субъект, принимающий предмет инвестиций;

- объект инвестиций - область приложения предмета инвестиций.

В связи с этим представляется необходимым дать общее определение инвестиций. По мнению автора, инвестиции - это вложение реальных и финансовых активов в развитие различных сфер жизни общества как с целью извлечения прибыли, так и с целью поддержания функционирования жизненно важных для экономики объектов вложения средств.

Резюмируя сказанное выше, автор приходит к выводу о сущности этой социально-экономической категории. Она состоит в следующем - инвестиции носят всеобщий, базисный, объективный характер, отражают уровень развития производства и являются системой экономических отношений, складывающихся в процессе производства по поводу аккумулирования и использования ресурсов в целях общественного развития.

Взяв за основу наиболее широкую классификацию инвестиций, используемую в мировой практике, автор предлагает ступенчатую классификацию форм инвестиций по ряду признаков, включающих характеристики субъекта, объекта и предмета инвестиций (таблица 1). 
Таблица 1 - Классификация форм инвестиций

\begin{tabular}{|c|c|c|}
\hline \multicolumn{3}{|l|}{ ИНВЕСТИЦИИ } \\
\hline По направлениям вложения средств & & $\begin{array}{l}\text { прямые } \\
\text { портфельные } \\
\text { прочие }\end{array}$ \\
\hline По величине риска & & $\begin{array}{l}\text { надежные } \\
\text { рисковые }\end{array}$ \\
\hline $\begin{array}{l}\text { По институциональному составу субъекта инвестиро- } \\
\text { вания }\end{array}$ & & $\begin{array}{l}\text { частные } \\
\text { государственные } \\
\text { совместные }\end{array}$ \\
\hline По продолжительности инвестиционного цикла & & $\begin{array}{l}\text { краткосрочные } \\
\text { среднесрочные } \\
\text { долгосрочные }\end{array}$ \\
\hline \multirow[t]{2}{*}{ По источникам финансирования } & & $\begin{array}{l}\text { бюджетные: } \\
\text { - федеральные } \\
\text { - региональные } \\
\text { - местные }\end{array}$ \\
\hline & & $\begin{array}{l}\text { частные: } \\
\text { - банковские } \\
\text { - коммерческие } \\
\text { банковские } \\
\text { коммерческие }\end{array}$ \\
\hline По эффективности & ные & $\begin{array}{l}\text { высокоэффектив- } \\
\text { среднеэффективные } \\
\text { низкоэффективные }\end{array}$ \\
\hline
\end{tabular}

Иностранные инвестиции - это не только валютные средства, но и современная технология, и организация, опыт установления и поддержания деловых контактов с зарубежными странами [4, с.309].

Иностранные компании везут с собой богатый управленческий опыт, оказывают помощь в сфере консультационных, финансовых, сбытовых услуг и т.д. Нельзя также сбрасывать со счетов создание новых рабочих мест с достойной оплатой труда, новые технологии, увеличение налоговых поступлений. Зачастую все это сопровождается развитием инфраструктуры региона, социальной поддержки, а также оживлению и развитию второстепенных производств.

Иностранные инвестиции дают реальную возможность использования их для реструктуризации, диверсификации и оживления производственной сферы. В пользу гипотезы о важной роли иностранных инвестиций в экономическом росте говорит опыт стран, осуществивших в последние десятилетия резкий скачок в экономическом развитии (Китай, Республика Корея, Тайвань, Сингапур).

Привлекая иностранные инвестиции, страна-реципиент стремится: получить доступ к зарубежной передовой технологии; пополнить внутренние источники накопления; использовать иностранный опыт управления для повышения эффективности производства; уменьшить неоправданный импорт и сократить расходы в свободно конвертируемой валюте; расширить экспорт, в особенности готовой промышленной продукции и обеспечить таким образом рост валютных поступлений. В результате страна добивается ускорения темпов 
экономического роста. Успехи в экономике одновременно и привлекают иностранных инвесторов, и обеспечивают стране достойное положение в мире.

Несмотря на всю значимость иностранных кредитов, стоит отметить, что отрицательным моментом привлечения иностранных кредитов является то обстоятельство, что, как и любой кредит, иностранный, требует погашения основного долга и причитающихся по нему процентов, что отвлекает значительные средства из национальной экономики, увеличивает внешний долг странызаемщика. Это уже сказывается на экономической, а порой и на политической независимости страны должника. Отвлечение больших сумм может также негативно сказаться на устойчивости денежного обращения.

Иностранные кредиты не всегда направляются в реальный сектор экономики, способный дать реальную отдачу через определенное время. Нередко кредиты направляются в нематериальную сферу, связанную с сохранением социального равновесия, созданием необходимой инфраструктуры, поддержанием национальной валюты.

«Иностранные инвестиции, - отмечал М.Портер, - поступающие в страну, никогда не решают проблемы обеспечения конкурентоспособности этой страны $[5,895$ c. $]$.

Несмотря на огромную роль внешних источников инвестиций никто никогда не заинтересован в подъеме и развитии экономики другой страны до такой степени, чтобы потом получить в лице этой страны серьезного конкурента. Тем более, что при иностранном финансировании всегда стоит вопрос о репатриации прибыли, возврате инвестиций. Известно, что чрезмерный отток денег из страны (в случае если сумма репатриируемой прибыли превышает поступления от экспорта с расчетом импорта) возникает валютный кризис. Именно поэтому стимулирование внутренних инвестиций имеет важное значение для устойчивого развития национальной экономики.

Современная действительность говорит о приоритетности внутренних инвестиций. Именно поэтому в ведущих странах мира в общем (объеме инвестиций решающую роль (от 85\% до 95\%) играют внутренние источники. Для дальнейшего поступательного движения экономики страны вперед, для занятия своего достойного места среди наиболее развитых индустриальных держав, полноценного участия в международном разделении труда, необходимо максимально мобилизовать внутренние ресурсы, эффективно их использовать, чтобы придать новый, дополнительный импульс проводимым в стране реформам, а также развивать и налаживать международное предпринимательство, отдавая предпочтения новейшим тенденциям и достижениям научной, технической, технологической и управленческой мысли.

Инвестиционные механизмы всегда привлекали внимание экономистов в силу того, что вложение капиталов - это крайне ответственное экономическое решение с наиболее отделенным и плохо прогнозируемым конечным результатом, от которого зависят и чисто предпринимательские частные результаты и общее состояние и развитие национальной экономики. 
Автор под понятием «механизм привлечения иностранного капитала в национальную экономику» имеет в виду взаимосвязанную и взаимообусловленную совокупность мер по регулированию и стимулированию их притока с целью обеспечения устойчивого социально-экономического развития страны и равноправного вхождения в мировое сообщество.

Механизм привлечения инвестиций является неотъемлемым элементом общей экономической политики, должен разрабатываться и реализоваться путем взаимодействия государственных органов управления республиканского и регионального уровня.

Под элементами механизма привлечения инвестиций понимаются взаимосвязанные методы правового, экономического и административного характера, определяющие правила и процедуры реализации всего комплекса операций, связанных с осуществлением инвестиций.

Формирование механизма привлечения иностранных инвестиций представляет собой сложный, длительный по времени процесс, планирование и реализация которого осуществляются в рамках разработанной концепции либо программы организации финансирования посредством зарубежных инвестиций объекта инвестирования. Формирование механизма привлечения иностранных инвестиций, по мнению автора, должно исходит из необходимости решения следующих задач:

во-первых, создание благоприятной среды и условий для инвестирования национального капитала, вывезенного за рубеж;

во-вторых, повышения рейтинга страны за счет снижения некоммерческих рисков;

в-третьих, создание благоприятных условий для привлечения иностранных инвестиций, главным среди которых является стабильность налогового режима.

Автор полагает, что рассмотрение вопроса привлечения инвестиций целесообразно вести с учетом причинно-следственной цепочки связей, определяющих позитивность или негативность деятельности иностранного инвестора по отношению к национальным интересам инвестируемой страны (рисунок 1)

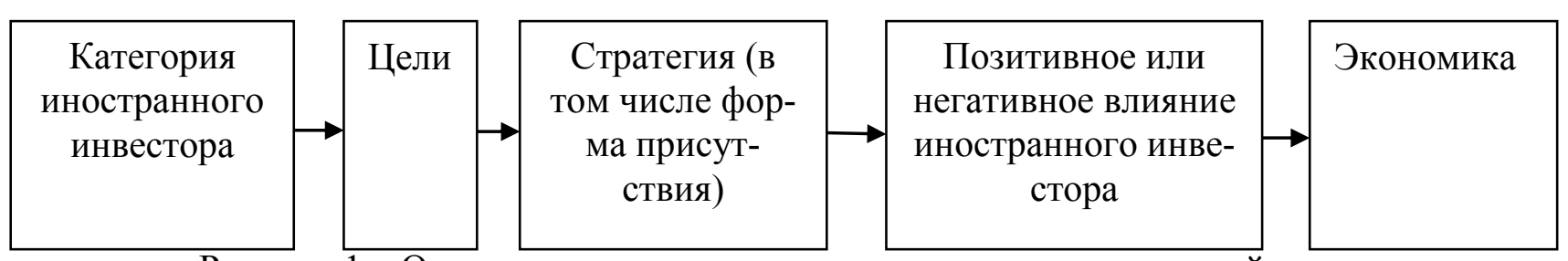

Рисунок 1 - Отношения иностранного инвестора и национальной экономики

На основе анализа зарубежной экономической литературы автором выделены цели иностранного инвестирования. Цели и авторы их анализирующие систематизированы в таблице 2. 
Таблица 2 - Цели иностранного инвестирования и авторы их анализирующие

\begin{tabular}{|c|c|}
\hline \multicolumn{2}{|c|}{ Цели иностранного инвестирования } \\
\hline Цели & Авторы их анализирующие \\
\hline $\begin{array}{l}\text { Дополнительные доходы и более высокие } \\
\text { прибыли }\end{array}$ & $\begin{array}{l}\text { С.Г. Хаймер, Р.Е. Кейвз, М.Н. Уикс, Д.М. Шапи- } \\
\text { ро, Р.А. Баад, Р.Д. Пирс, Р.Х Шварц, Т.С. Вална }\end{array}$ \\
\hline $\begin{array}{llll}\text { Устранение } & \text { конкурентов } & \text { в } & \text { стране- } \\
\text { получателе } & & & \end{array}$ & Р. Вернон, К. Коджима, Й. Ахаронн \\
\hline Диверсификация деятельности & $\begin{array}{l}\text { Ф. Хорн, Р.Петерс, К. Тьюгендхэт, Р. Вернон, К. } \\
\text { Коджима, С.А. Новаковски, Т.М. Ричардс, } \\
\text { О.Е. Уильямсон, М. Керн, М. Штано, Д. Лессард }\end{array}$ \\
\hline Захват новых рынков & $\begin{array}{lll}\text { К. Мауль, } & \text { Й. Ахарони, } & \text { Б.Баласса, } \\
\text { Ч. Киндлебергер, Г. Роймер, П, Юль } & \end{array}$ \\
\hline Обеспечение поставок сырья и продукции & Р.Е. Крайнер, А.К. Северн, Х. Хенсель, А. Шеер \\
\hline Ослабление конкурентов в своей стране & Грэм, С.Ф. Бергштен, Т. Хорс \\
\hline $\begin{array}{l}\text { Получение производственных, торговых вы- } \\
\text { год }\end{array}$ & П. Юль, Б. Корден, А.Я. Холландер \\
\hline
\end{tabular}

Иностранные инвестиции играют немаловажную роль как средство трансферта технологий. Однако в практике иностранного инвестирования это направление носит непоследовательный характер. Другим аспектом влияния иностранного инвестирования на принимающую экономику является его воздействие на использование трудовых и материальных ресурсов. Прежде всего это находит выражение в том, что под влиянием иностранных инвестиций, выступающих как в форме ссудного капитала и создания современных производств, так и в форме передачи технологий, в стране-импортере формируется новый тип рабочей силы. Использование иностранных инвестиций в материально-сырьевых секторах экономики страны-импортера может иметь двоякое воздействие на экономику. С одной стороны, это приводит к истощению национальных богатств даже при их эффективном использовании, а весь непосредственный результат от применения материальных и трудовых факторов производства приходится на долю иностранного инвестора. В этом случае эффект для принимающей экономики носит косвенный характер. С другой стороны, он может быть позитивным в тех случаях, когда рабочая сила приобретает новое качество, производство ориентируется на современные стандарты, снижается напряженность на потребительском рынке, совершенствуется отраслевая и территориальная структура производства и т.д.

Иностранные инвестиции не могут не воздействовать и на международный аспект экономического развития страны. Их влияние на торговый и платежный баланс различно в зависимости от периода времени. В частности, краткосрочное влияние импорта инвестиций на торговый баланс принимающей страны, как правило, носит негативный характер, так как увеличение импорта необходимых материалов и оборудования в первоначальный период иностранного ин- 
вестирования не сопровождается ростом объема производства. А вот развитие импортозамещающих производств приводит в дальнейшем к достижению положительного сальдо.

В целом иностранное инвестирование способно оказать позитивное воздействие на социально-экономическое развитие той или иной страны при наличии в ней четкой концепции, ориентированной на структурированный прием иностранных инвестиций в интересах развития национальной экономики, стимулирующей инвестирование в те отрасли и в те направления, где существует наиболее острая потребность в капиталовложениях. Следовательно, только сочетание протекционизма и либерализации внешнеэкономических связей обеспечивает иностранному инвестированию позитивный эффект, выступающему в роли катализатора инвестиционных процессов в экономике и способствующему социально-экономическому росту.

Стимулировать приток иностранного капитала в народное хозяйство достаточно сложная, но решаемая задача. В мировой практике это достигается в основном двумя способами: предоставлением иностранным инвесторам различных льгот либо гарантий политического и финансового характера, закрепляемых в законодательстве.

Однако стоит очень внимательно отнестись к выбору механизмов регулирования и, особенно, стимулирования притока иностранных инвестиций. Упущенные фискальные доходы могут существенно превысить экономический эффект от привлеченных инвестиций. В тоже время удачно подобранный набор инструментов механизма регулирования инвестиций может обернуться дополнительным конкурентным преимуществом для страны. Задача осложняется тем, что готовых априорных рецептов использования международного опыта, кроме указания некоторых общих направлений не существует. При формировании набора инструментов регулирования инвестиций решающее значение имеют эмпирические данные национальной экономики, экономическая идеология правительства и индивидуальные задачи развития страны. Привлекая иностранные инвестиции необходимо выработать такие побудительные механизмы, которые, во-первых, были бы понятны и отвечали ожиданиям инвесторов и, во-вторых, были бы конкурентоспособными относительно тех схем, которые предлагаются странами-конкурентами.

Вопросам разработки механизма привлечения иностранных инвестиций для нужд конкретной страны или региона посвящен ряд научных и научнопрактических исследований зарубежных экономистов. Такие организации как Всемирный банк, МВФ, ОЭСР постоянно проводят исследования и консультации, посвященные вопросам привлечения инвестиций.

Автор придерживается точки зрения ОЭСР, которая в своих исследованиях механизма привлечения инвестиций в страны с переходной экономикой определяет следующие меры, которые должна принимать страна-реципиент для активизации привлечения внешнего капитала: 
1. Фискальные меры (ускоренная амортизация, преференции по таксам и тарифам, освобождение от налогов с предприятий, особые ставки налогов и др.);

2. Финансовые меры (гранты, преференциальные займы, гарантии займов и др.);

3. Прочие меры (инфраструктурная помощь, государственные контракты, предоставление дополнительных или особых услуг, учреждение свободных торговых и таможенных зон и др.).

Фискальный механизм представляет собой меры, направленные на снижение налогового бремени и на сокращение периода окупаемости инвестиций, a, по существу, это манипуляция общей для всех системой норм и правил (процентными ставками, ставками налогов, порядком налогообложения, правилами залога, инструкциями по взиманию пошлин и многое другое). В современных условиях наиболее важными фискальными стимулами являются следующие:

1) «налоговые каникулы»;

2) налоговый кредит;

3) отмена отдельных налогов;

4) ускоренный режим амортизационных списаний, особенно на первых стадиях работы;

5) льготы в отношении средств, используемых на инвестиции и реинвестиции;

6) разрешение зачета потерь, полученных в первый период работы, в счет будущих прибылей;

7) льготы косвенного налогообложения, в частности, снижение экспортных пошлин, сокращение налогообложения экспортно-ориентированного производства и др.

Общая черта фискальных льгот заключается в том, что они применяются по отношению к уже вложенным инвестициям

Международный опыт показывает, что для привлечения иностранного капитала фискальным стимулам отдают предпочтение в основном развивающиеся страны и страны с переходной экономикой, тогда как страны с рыночной экономикой в своей практике опираются на финансовые стимулы и вложения в инвестиционную инфраструктуру. К числу финансовых стимулов относятся следующие:

1) прямые субсидии на покрытие части капитальных расходов, производственных или маркетинговых расходов конкретного инвестиционного проекта;

2) предоставление льготных кредитов или гарантий по кредитам;

3) гарантированные экспортные кредиты;

4) правительственное страхование льготных кредитов, предоставляемое для некоторых видов риска. Например, при изменении курса валюты, девальвации или по некоммерческим рискам - экспроприации, изменении политического строя страны;

5) частичное возмещение инвестиций в землю, здания и оборудование;

6) государственное участие в акционерном капитале и др. 
Особенность финансовых льгот заключается в том, что они, в отличие от фискальных стимулов, предоставляются, как правило, до начала инвестирования, а это требует наличия свободных средств в государственном бюджете, поэтому для развивающихся стран их предоставление является весьма проблематичным, так как имеет риск для бюджета в плане доходных поступлений.

Под прочими побудительными механизмами привлечения инвестиций подразумеваются меры, способствующие совершенствованию технических и операционных условий для иностранных компаний, меры, направленные на создание общей обстановки эффективного функционирования иностранного капитала - от обеспечения необходимыми факторами производства и информацией до развития различных коммуникаций. Среди прочих методов стимулирования иностранных инвестиций следует выделить следующие:

1) государственное финансирование развития местной инфраструктуры, т. е. подъездные автомобильные и железнодорожные пути, причалы; развитие телекоммуникаций, водоснабжения, дренажных систем, энергообеспечения и т. п.;

2) внедрение международных стандартов бухгалтерского учета, обеспечивающего прозрачность финансового положения предприятий, необходимой для потенциальных инвесторов;

3) субсидирование услуг, в том числе помощь в нахождении источника финансирования, разработке проектов, предоставление информации о конъюнктуре рынков, наличии сырья, помощь в подготовке кадров, предоставление технических возможностей для развития ноу-хау или улучшение контроля за качеством;

4) предоставление возможности иностранным компаниям участвовать в открытых тендерах на равных правах с местными компаниями;

5) информационные туристические визиты инвесторов за счет государства и др.

Все три типа рассмотренных механизмов привлечения инвестиций сопряжены с потерями для предоставляющих их стран как в краткосрочной, так и в среднесрочной перспективе, но зачастую эти потери оправданы, поскольку в долгосрочном плане их можно восполнить путем возросшего притока иностранного капитала в страну и активизации деятельности национального капитала.

Для зарубежного инвестора решающее значение имеет наличие природных ресурсов, политическая и экономическая стабильность, надежность правовой и административной систем, адекватность институтов поддержки - банковской, транспортной и прочих сфер инфраструктуры, свобода перевода прибыли, уровень квалификации и стоимость рабочей силы. Если эти факторы благоприятные, то льготы, предоставляемые страной-реципиентом капитала, могут сыграть наиболее эффективную роль в принятии инвестором решения о вложении капитала.

В то же время необходимо отметить, что по вопросу о возможности предоставления иностранным инвесторам дополнительных льгот по сравнению с 
отечественными инвесторами существует некоторое расхождение взглядов. Основные аргументы против предоставления льгот иностранным инвесторам следующие: нарушается принцип равенства прав инвесторов вне зависимости от национальной принадлежности, кроме того, - данными льготами легко могут воспользоваться и отечественные инвесторы, приняв форму (с помощью оффшорных технологий) иностранного капитала, что отчасти подталкивает отечественный капитал к смене национальной формы. Основные аргументы за предоставление дополнительных гарантий прямым иностранным инвесторам сводятся к следующему.

Во-первых, в современных условиях невозможно предоставить всем инвесторам условия деятельности (информационное обеспечение, возможности использования судебных процедур и т. д.), соответствующие мировым стандартам, к которым привыкли крупные иностранные инвесторы.

Во-вторых, наиболее успешный опыт привлечения крупных прямых инвестиций продемонстрировали страны, предоставляющие значительные льготы прямым иностранным инвесторам.

\section{ВЫВОДЫ}

Таким образом, в современном мире устойчивое развитие национальной экономики невозможно без эффективного участия в мирохозяйственных процессах, в том числе без активного использования преимуществ от привлечения прямых инвестиций из-за рубежа - получение дополнительного источника капитальных вложений в производство товаров и услуг, в ряде случаев осуществляемый в виде передачи технологии, ноу-хау, новейших методов управления; получение инвестиций, которые не ложатся бременем на государственный бюджет и внешний долг. Неотъемлемым элементом общей экономической политики является механизм привлечения иностранных инвестиций - взаимосвязанная и взаимообусловленная совокупность мер по регулированию и стимулированию их притока с целью обеспечения устойчивого социальноэкономического развития страны. Внутренняя среда механизма привлечения иностранных инвестиций представляет собой собственно политику в отношении инвестиций и в области либерализации торговли, а внешняя - это макроэкономическая политика государства, главным образом вопросы денежной, валютной и налоговой политики. Автор выделяет три типа механизмов привлечения инвестиций, часто используемых в разнообразных комбинациях, фискальные, финансовые и прочие. Фискальный механизм представляет собой меры, направленные на снижение налогового бремени и на сокращение периода окупаемости инвестиций, а, по существу, это манипуляция общей для всех системой норм и правил (процентными ставками, ставками налогов, порядком налогообложения, правилами залога, инструкциями по взиманию пошлин и многое другое); финансовый - предоставление кредитов и субсидий, что требует наличия свободных средств в государственном бюджете, и поэтому используется, как правило, странами с развитой экономикой. Под прочими побудительными механизмами привлечения инвестиций подразумеваются меры, спо- 
собствующие совершенствованию технических и операционных условий для иностранных компаний, меры, направленные на создание общей обстановки эффективного функционирования иностранного капитала - от обеспечения необходимыми факторами производства и информацией до развития различных коммуникаций.

\section{ЛИТЕРАТУРА}

1. Шарп У.Ф., Александер Г.Д., Бэйли Д.В. Инвестиции. М: Инфра-М. 1997

2. Бочаров В.В. Методы финансирования инвестиционной деятельности предприятий. - М.: Финансы и статистика, 1998.

3. Инвестиционно-финансовый портфель, /под ред. Петракова Н. Я. М.: Соминтек, 1993.

4. «Большой экономический словарь» А.Н Азрилияна. Москва. Институт новой экономики. 2002.

5. Портер М. Международная конкуренция /Под ред. В.Д. Щетинина. М.: Международные отношения, 1993. 